\title{
Flow cytometry in Spermatology: A bright future ahead
}

C. Ortega-Ferrusola, M. C. Gil, Heriberto Rodriguez-Martinez, L. Anel, F. J. Pena and P. Martin-Munoz

The self-archived postprint version of this journal article is available at Linköping University Institutional Repository (DiVA):

http:// urn.kb.se/ resolve?urn=urn:nbn:se:liu:diva-143358

N.B.: When citing this work, cite the original publication.

Ortega-Ferrusola, C., Gil, M. C., Rodriguez-Martinez, H., Anel, L., Pena, F.J ., Martin-Munoz, P., (2017), Flow cytometry in Spermatology: A bright future ahead, Reproduction in domestic animals, 52(6), 921-931. https:// doi.org/ 10.1111/ rda.13043

Original publication available at:

https:// doi.org/ 10.1111/rda.13043

Copyright: Wiley (12 months)

http:// eu.wiley.com/WileyCDA/ 


\section{Flow cytometry in Spermatology: a bright future ahead}

${ }^{3}$ Ortega Ferrusola C, ${ }^{1}$ Gil MC, ${ }^{2}$ Rodriguez Martínez H, ${ }^{3}$ Anel L, ${ }^{1 *}$ Peña FJ ${ }^{1}$ Martin Muñoz P

${ }^{1}$ Laboratory of Equine Reproduction and Equine Spermatology, Veterinary Teaching Hospital, University of Extremadura, Cáceres, Spain. ${ }^{2}$ Department of Clinical and Experimental Medicine, Faculty of Health Sciences Linköping University, Linköping, Sweden ${ }^{3}$, Reproduction and Obstetrics Department of Animal Medicine and Surgery, University of León, Spain

*Correspondence to Dr. FJ Peña, Veterinary Teaching Hospital, Laboratory of Equine Spermatology and Reproduction, Faculty of Veterinary Medicine, University of Extremadura Avd. de la Universidad s/n 10003 Cáceres Spain. E-mail mailto:fjuanpvega@unex.es

phone +34 927-257167

fax +34927257102

\section{Acknowledgements}

The authors received financial support for their studies from the Ministerio de Economía y Competitividad-FEDER, Madrid, Spain, grant AGL2013-43211-R, Junta de Extremadura-FEDER (GR 10010 and IB 16030) and the Swedish Research Councils VR (521-2011-6353) and Formas (221-2011-512). PMM is supported by a pre-doctoral 
grant from the Ministerio de Educación, Cultura y Deporte, Madrid Spain FPU13/03991. COF is supported by a post-doctoral grant from the Ministerio de Economía y Competitividad “Juan de la Cierva” IJCI-2014-21671.

Disclosure: the authors declare that there is not conflict of interest that may affect the impartiality of the information presented in this paper

\begin{abstract}
Techniques such as mass spectrometry have led to unprecedented knowledge of the proteins that are present in the spermatozoa of humans and other mammals. However, in spite of their high-throughput and fractioning techniques, most of the techniques in use only offer average values for the entire sperm population. However, ejaculate is very heterogeneous, and average values may mask relevant biological information.

The application of flow cytometry may overcome this disadvantage, allowing proteomic analysis at the single-cell level. Moreover, recent advances in cytometry, allowing multiple analyses within a single cell combined with powerful statistical tools, as an expanding subfield in spermatology, are described. The increased use of advanced flow cytometers in andrology laboratories will allow the rapid development of multiparametric, multicolor flow cytometry in andrology that will expand the clinical applications and research possibilities of flow cytometry-based proteomic approaches, especially in the subfields of clinical andrology and sperm biotechnology
\end{abstract}

Key words: sperm, subpopulations, proteome, flow cytometry 


\section{INTRODUCTION}

The spermatozoon is a highly differentiated cell that harbors the haploid male genome in a highly compact chromatin structure (Lindemann and Lesich 2016). The spermatozoon has a large tail with a midpiece rich in mitochondria, the organelles that provides energy via oxidative phosphorylation and have other important regulatory functions (Davila et al. 2016, Pena et al. 2015). Spermatozoa are generated in the seminiferous epithelium of the testis in a process called spermatogenesis. The initial cell in this process is the ad-basal spermatogonium, which experiences a series of mitotic divisions and commits to entering meiosis by becoming a spermatocyte (spermatocytogenesis). Meiotic recombination takes place through reductional divisions inside the adluminal protected compartment of the seminiferous tubule. When meiosis is complete, haploid, re-combined round spermatids are generated (Fraser and Lin 2016). These cells will experience dramatic changes in their transformation (spermiogenesis) to testicular spermatozoa that will be released to the seminiferous tubule lumen at spermiation (spermatoteleosis), after losing most of its cytoplasm when engulfed by the Sertoli cells. Spermiogenesis broadly implies the transformation of one of the centrioles into a flagellum, around which part of the mitochondria arranges to build the sperm tail together with specific columns of proteins. Transformation also implies remodeling of the cell nucleus, to which a modified lysosome is attached to form the acrosome, concomitant with extensive remodeling and compaction of the chromatin. This is accompanied by the acquisition of epigenetic marks such as DNA methylation, histone modifications and regulation by small RNAs (Fraser and Lin 2016). The intensive compaction and remodeling of the chromatin by replacement of 
histones with protamines protects the paternal genome through its journey to fertilize the egg and silences all nuclear transcription. This implies that there is no protein synthesis in mature spermatozoa, which rely on post-translational modifications (PTM) to regulate their function (Fraser and Lin 2016). Additionally, spermatozoa experience further maturational processes as they transit through the epididymis, where further maturation of protamines is present. The final step of maturation in the female genital tract is called capacitation (Rodriguez-Martinez 1992). This later process implies intense redox-regulated PTM. Due to the inability of the spermatozoa to synthetize proteins de novo, major functions of the spermatozoa such as motility and capacitation are tightly regulated, involving redox-dependent tyrosine phosphorylation of sperm proteins (O'Flaherty 2015). However, dis-regulation of these systems leads to oxidative stress and cell death (Morielli and O'Flaherty 2015)

Mammalian ejaculate is composed of spermatozoa, caudal epididymis fluid and the secretions of the accessory sexual glands. Because dynamic spermatogenesis is a continuous process, the sperm reserve in the epididymis tail is composed of many generations of spermatogenesis. Thus, not all of the ejaculated spermatozoa is from the same generation or present the same physiological status. A well-known, but frequently overlooked fact is that only one spermatozoon will reach the goal of fertilizing the oocyte. The concept of sperm heterogeneity was introduced in the 1990s (Glassy et al. 1984, Paradisi et al. 1996, Thurston et al. 1999, Abaigar et al. 1999), with the beginning of the new century witnessing intense research into the subpopulation structure of the ejaculate in humans and other mammals (Santolaria et al. 2015, Unates et al. 2014, Abad et al. 2013, Thilagavathi et al. 2012, Mendoza et al. 2012, Marti et al. 2011, Dorado et al. 2010, Ortega-Ferrusola et al. 2009, Druart et al. 2009, Quintero-Moreno et al. 2007, Pena et al. 2006, Satake et al. 2006, Pena et al. 2005b, Pena et al. 2005a, 
Martinez-Pastor et al. 2005, Chantler et al. 2004, Buffone et al. 2004, Correa-Perez et al. 2003, Thurston et al. 2001). The discovery of this ejaculate "heterogeneity" challenged the "competitive race model" of fecundation, in which large numbers of spermatozoa race towards the egg and compete to fertilize (Eisenbach and Giojalas 2006). In their journey to reach the oocyte, spermatozoa are exposed to different environments, and most spermatozoa succumb alongside sperm transport in the female. Only the best quality sperm reach the oviduct at the utero-tubal junction and form the sperm reservoir, where they are sequentially released in relation to ovulation (Hunter and Rodriguez-Martinez 2004, Hunter and Rodriguez-Martinez 2002). In fact, very few spermatozoa reach the oviduct; in humans, it is estimated that only 1 of every million ejaculated spermatozoa enter the Fallopian tubes (Eisenbach 2003, Eisenbach and Giojalas 2006), and only a small percentage of spermatozoa experience complete capacitation and are able to fertilize (Giojalas et al. 2004, Cohen-Dayag et al. 1995). The existence of redundant spermatozoa or spermatozoa with a function other than fertilization (perhaps assisting the fertilizing spermatozoa on their journey), is an intriguing hypothesis that is undermined by the fact that most spermatozoa are basically dying or already dead sperm (Roca et al. 2016). Research into sperm competition supports this line of reasoning. The study of sperm subpopulation structures includes morphological and kinematic studies. More recently, with the advent of the "omics" era to spermatology, detailed proteomic studies have been conducted (Agarwal et al. 2016, Bayram et al. 2016, Castillo et al. 2015, Huang et al. 2015, Kwon et al. 2014, Azpiazu et al. 2014, Aitken and Baker 2008). Proteomic approaches usually involve one- and two-dimensional electrophoresis (1/2-DE) for the separation of proteins, followed by mass spectrometry for peptide sequencing to facilitate protein identification. These techniques have yielded enormous advances in our knowledge of the sperm proteome in 
human and mammals. However, this approach provides average values at single time points and masks sperm heterogeneity. Thus, techniques for single cell analysis are required to study the heterogeneous complexity of ejaculate. In this paper, we argue that flow cytometry can be a major tool for proteome research in spermatology in the coming years, complementing current large-scale identification techniques. To prepare the present review, we conducted an exhaustive literature search using the PubMed, Science Direct and Scopus databases to identify proteomic studies in spermatozoa, with a particular focus on flow cytometry in humans and pertinent animal models. Our search focused on papers that were published in the last 5 years (2012-2016). Particular attention was paid to single-cell analysis using flow cytometry because excellent reviews are already available for general sperm proteomics (Castillo et al. 2015, Amaral et al. 2014b, Castillo et al. 2014, Amaral et al. 2014a, Azpiazu et al. 2014, Swegen et al. 2015, Aitken and Baker 2008).

\section{EJACULATED SPERMATOZOA ARE PHENOTIPICALLY DIFFERENT}

The heterogeneous nature of the mammalian ejaculate has been recognized to include not only genotypic diversity but also differences in phenotype; different subpopulations of spermatozoa can be distinguished based on morphometric and kinetic analyses (Nunez-Martinez et al. 2007, Nunez-Martinez et al. 2006, Pena et al. 2006, Pena et al. 2005a, Ortega-Ferrusola et al. 2009). This complexity has been identified in many biological systems (Newman and Weissman 2006, Newman et al. 2006) and its importance is also stressed in different aspects of medicine (Saadatpour et al. 2015, Sigal et al. 2006, Cohen et al. 2008), even leading to a consensus in andrology related to the limited value of the report of average values in the spermiogramme . The guidelines 
for the application of computer assisted sperm analysis (CASA) technology in the analysis of spermatozoa have indicated this fact and proposed that the spermatozoa should be classified into specific subpopulations related to relevant functional endpoint (Group 1998). More recently, flow cytometry has been used to identify specific sperm subpopulations capable of responding to specific stimuli (Escoffier et al. 2015) in relation to capacitation. These facts support the concept that only a small subpopulation of spermatozoa capacitates in humans (Gakamsky et al. 2008, Oren-Benaroya et al. 2008, Eisenbach and Giojalas 2006, Eisenbach 2003). This has profound implications for sperm proteomics, implying the existence of two distinct sperm subpopulations with potentially different proteomes: capacitated spermatozoa that can reach and fertilize the oocyte and spermatozoa that cannot capacitate properly and must be silently removed by phagocytosis in the absence of inflammatory reactions from the female genital tract (Eisenbach 2003). Spermatozoa experience selection in the female genital tract immediately after ejaculation (Sakkas et al. 2015). The deposition site varies with species; in humans, it occurs in the superior vagina near the cervical opening. Ejaculated spermatozoa encounter a hostile vaginal $\mathrm{pH}$ and an immediate inflammatory reaction response at the deposition site. In other species, the deposition site is located in the cervix or even the uterine lumen. These differences relate to the type, volume and anatomical characteristics of species. Ejaculates can have a single volume (as in ruminants) or be fractionated, as in human, canine, porcine or equine sperm. In fractionated ejaculate, the first portions of the ejaculate are always sperm-rich; the seminal plasma is protein-poor, while the next spurts of the ejaculate are sperm-poor but the seminal plasma is protein-rich. In humans, the first jets of ejaculate contain most of the spermatozoa bathed in prostate-dominated secretion. The secretion is acidic due to the epididymis fluid. Because of the prostate secretion, this portion does not coagulate 
while bathing the os cervix. All these characteristics favor the immediate entry of a subpopulation of spermatozoa into the cervical canal via capillarity. The rest of the ejaculate contains fewer spermatozoa and a dominance of secretion of the seminal vesicles. This portion of the ejaculate coagulates because it is more protein-rich. The coagulum traps spermatozoa in the vagina but also signals the female genital immune system. The coagulum often resorbs in minutes in vivo and readily egresses from the vagina by back-flow. Thus, this sperm subpopulation does not participate in fertilization. In vitro, praxis is to collect the entire ejaculate (all jets) into a single lab tube, which is a poor mimic of the physiological state. The spermatozoa that fortuitously escape this initial selection (e.g., those in the cervical canal) follow a new selection process. Spermatozoa with poor motility and abnormal morphology do not traverse the channels of sialic acid in the endocervix. Once in the uterus, spermatozoa rapidly progress upwards, due to contractions of the myometrium. In all species yet studied, there are strong, although transient, inflammatory vaginal, cervical and uterine reactions that are intended to eliminate foreign spermatozoa and the proteins of the seminal plasma, along with eventual microorganisms. This reaction is particularly strong in horses, a species in which the cervix does not constitute a major barrier to spermatozoa. Finally, the surviving (often vanguard) spermatozoa reach the utero-tubal junction, which exerts final sperm selection based on sperm morphology, motility and the battery of surface proteins exposed by the spermatozoa (Sakkas et al. 2015). These selection processes in the female reproductive tract all result in a spermatozoa reduction of 5 to 6 orders of magnitude in humans. This underlines sperm heterogeneity and the need for identifying the fertilizing sperm population in the whole ejaculate. 


\section{AVERAGE VALUES DO NOT PROVIDE ACCURATE INFORMATION OF SPERM BIOLOGY}

When a semen sample is taken for sperm analysis or to study sperm biology, only average values are reported, and readouts are given at a single time point. Considering the heterogeneous nature of the mammalian ejaculate and strict selection in the female reproductive tract, it is clear that average values mask important information. Traditional whole-sperm proteomic approaches such as 2D polyacrylamide gel electrophoresis (2D-PAGE), mass spectrometry (MS), and differential in-gel electrophoresis (DIGE) have allowed for the identification of numerous sperm-specific proteins (Agarwal et al. 2016, du Plessis et al. 2011). Studies of the sperm proteome have demonstrated how post-translational modifications such as phosphorylation, glycosylation, proteolytic cleavage and mutation bring about physiological changes in spermatozoa function (Aitken and Baker 2008, Baker 2016). Furthermore, proteomic analysis has allowed for the study of spermatozoa in different functional states, e.g., immature vs. mature, uncapacitated vs. capacitated, normal vs. defective, all of which impact the reproductive potential of the male (Barazani et al. 2014, Gupta et al. 2014, Agarwal et al. 2014, du Plessis et al. 2011). More traditional techniques used to study sperm biology, such as western blotting, are limited by the reporting of average values (Hoppe et al. 2014) (see fig. 1). In addition, only a small percentage of ejaculated spermatozoa experience capacitation, and thus the fertilizing population is formed by a relative small sperm number that is easily masked by any technique other than singlecell analysis.

SINGLE CELL ANALYSIS IN SPERM PROTEOMICS: FLOW CYTOMETRY 
Detailed descriptions of the sperm proteome of humans and other mammals are available (Swegen et al. 2015, Azpiazu et al. 2014, Amaral et al. 2014b, Amaral et al. 2014a) and provide useful information that can be used in single-cell analysis proteomic studies with the aid of flow cytometry. This approach allows consideration of the complex and heterogeneous nature of the ejaculate, thereby improving the quality of the information gathered. When signaling pathways in spermatozoa are considered, for example, only a fraction of the ejaculated spermatozoa undergoes capacitation (Escoffier et al. 2015). Due to the silencing of nuclear transcription in ejaculated spermatozoa, post-translational modifications of existing proteins are necessary for proper sperm function. These modifications include phosphorylation, glycosylation, disulfide cross-linking, ubiquitination, acetylation and methylation (Baker 2016). Protein tyrosine phosphorylation plays an important role in capacitation. The oxidation of cholesterol facilitates its efflux from the plasma membrane, but oxidation also inactivates tyrosine phosphatases and the stimulation of cAMP production (Aitken 2011, Aitken and Curry 2011). The influx of calcium and bicarbonate ions also stimulates soluble adenylyl cyclase (sAC), which converts ATP to cAMP. In turn, sAC regulates protein kinase A (PKA), which phosphorylates proline-rich tyrosine kinase 2 (PYK2) and finally leads to a general increase in the tyrosine phosphorylation of many proteins (see (Baker 2016) for a detailed review).

Glycosylation of N-or O-linked residues is also a major post-translational modification in spermatozoa. This modification appears to play major roles in capacitation, together with a well-known role in the maturation of spermatozoa through epididymal transit and a means of spermatozoa to evade immune detection in the female reproductive tract 
(Baker 2016). The formation of disulfide bonds, acetylation and ubiquitination are also important PTM in spermatozoa.

Techniques for single sperm cell analysis are required, ideally allowing the noninvasive quantification of molecular dynamics and sperm behavior over time. The dynamic and low-abundance nature of phosphorylated proteins makes the study of the phosphoproteome a challenge (Polat and Ozlu 2014). Miniaturized construction of analytical systems have been proposed to study the phosphoproteome at the single-cell level (Polat and Ozlu 2014).

Flow cytometry is now the central throughput method for simultaneous single-cell analysis of multiple proteins (Hoppe et al. 2014). Recent developments such as mass cytometry allow simultaneous detection of dozens of antigens in single cells (Nicholas et al. 2016, Spitzer and Nolan 2016). Although this technology is widely used in hematology, immunology and stem cell research, similar developments have not yet occurred in spermatology, even though similar developments can be envisioned. Similar to blood cells, spermatozoa are individual cells in suspension and are thus suitable for advanced flow cytometry. Phospho-proteomic approaches based on flow cytometry have been used in different fields of biology and medicine (Perez and Nolan 2006), and similar approaches are beginning to be used in spermatology (Gallardo Bolanos et al. 2014b, Pena et al. 2016, Perez and Nolan 2006, Krutzik et al. 2004). Flow cytometry is reinventing itself as a powerful tool for the study of sperm biology and clinical andrology, perhaps as a specific branch that could be termed flow-spermetry. 


\section{Single cell flow-proteomics and reproductive biotechnology}

Phosphoflow cytometry has been defined as the use of fluorochrome-conjugated antibodies with molecules phosphorylated during signaling cascades, allowing the analysis of signaling networks within complex cell populations and providing quantitative data of phosphorylation events at the single-cell level (Davies et al. 2016, Krutzik and Nolan 2003, Hale and Nolan 2006, Oberprieler and Tasken 2011)

Phospho-proteomic approaches using flow cytometry have been used to disclose the role of the phosphorylation status of Akt on sperm survival after ejaculation (Gallardo Bolanos et al. 2014a, Gallardo Bolanos et al. 2014b). Because spermatozoa are transcriptionally silent cells that depend on post-translational modifications to regulate their function, the study of the sperm phospho-proteome is of utmost relevance. Proteins involved in apoptosis have been identified in proteomic studies (Amaral et al. 2014a), and flow cytometry has allowed the investigation of this pathway in spermatozoa. This particular area constitutes a good example on how large sets of proteomic data can be used in functional studies at the single flow-sperm cell level. In stallion spermatozoa, full-length and cleaved caspases 3 and 7 have been identified in our laboratory using western blotting, immunocytochemistry and flow cytometry (Ortega-Ferrusola et al. 2008). Functional studies have demonstrated that cleaved caspase 3 increases with cryopreservation, a procedure that is widely used in animal breeding but leads to accelerated sperm senescence. Experiments using multi-parametric flow cytometry have shed light on the mechanisms of this cryopreservation-induced premature sperm senescence, which at the same time demonstrates the value of this approach to complement proteomic studies in spermatology. Initial studies indicated that during cryopreservation, spermatozoa experience osmotic shock that leads to membrane 
rupture and cell death, which results in an average 50\% viability of spermatozoa during the procedure. The surviving spermatozoa experience further changes in physiology, resulting in a reduced lifespan in the female reproductive tract. Flow cytometry has demonstrated that this sperm subpopulation expresses active caspase 3, triggered by the loss of ROS homeostasis and the increased production of 4-hydroxynonenal (Martin Munoz et al. 2015). Other apoptotic proteins have been identified in mammalian spermatozoa, including cleaved poly ADP-ribose polymerase (Casao et al. 2015). Similar phenomena occur in other species, including humans (Thomson et al. 2009, Jeong et al. 2009, Martin et al. 2004, Pena et al. 2003). This approach also allows the identification of samples that will better survive cryopreservation (Martin Munoz et al. 2016), which is of great interest for animal breeding, for which the frozen semen market is a major component. This approach will greatly improve the profitability of the industry by reducing the number of low quality samples. Detailed research into the molecular and proteomic changes induced by cryopreservation is considered pivotal to improve this technology in humans and animals (Kopeika et al. 2015, Pena et al. 2011).

\section{Single cell flow- proteomics and male fertility}

Male factor infertility accounts for 30\% of all infertility problems observed in couples requiring assisted reproduction, with $30 \%$ of the cases of male infertility classified as idiopathic. Moreover, delayed parenthood is linked to numerous problems in children born due to increased sensitivity to oxidative stress of spermatozoa in aged men (Charlton 2007, Tang et al. 2006, Tarin et al. 1998, Ozkosem et al. 2015, Morielli and O'Flaherty 2015). Traditional semen analysis is based on light microscopy and has been more recently aided by computerized systems and flow cytometry. Flow-proteomic 
approaches have been recently incorporated to investigate the molecular basis of male infertility. Studies focused on the proteomics of asthenozoospermia have identified proteins associated with energetic metabolism, protein folding/degradation, vesicle traffic and the cytoskeleton (Amaral et al. 2014b). Detailed sperm-flow proteomics analysis has been conducted in this area; flow cytometry has allowed the study of $\alpha$ tubulin acetylation in motile and immotile sperm fractions of normo- and asthenospermic individuals (Bhagwat et al. 2014). Whereas the subpopulation of immotile spermatozoa in normozoospermic patients showed no changes with respect to the motile population, the reduced levels of $\alpha$-tubulin and acetylated $\alpha$-tubulin were evident in asthenozoospermic patients. These observations suggest that this reduced acetylation is an inherent anomaly in these spermatozoa (Bhagwat et al. 2014), as tubulin acetylation is considered a PTM associated with microtubule stability. Flowproteomic studies have also investigated proteomic changes related to asthenozoospermia in obese patients (Liu et al. 2015). Reduced expression of two proteins was evidenced in these patients: endoplasmic reticulum protein 57 (ERp57) and actin related protein (ACTRT2). Interestingly, fluorescence intensity of ERp57 and ACTRT2 (equivalent to protein expression level), was negatively correlated with Body Mass Index (BMI). At the same time, intensity was positively correlated with sperm motility. Angiotensin II type 2 receptor has been investigated using flow cytometry in human spermatozoa (Gianzo et al. 2016). The expression of this protein was reduced in asthenozoospermic patients. Sperm-borne oocyte activating factors (SOAF) are necessary to initiate intracellular calcium release and embryo development. Postacrosomal WW binding protein (PAWP or WBP2NL) has recently been proposed as a major SOAF (Aarabi et al. 2015, Aarabi et al. 2014b), and its expression was studied using flow cytometry (Aarabi et al. 2014a). The levels of PAWP expression are 
correlated with the fertilization rate and normal embryonic development after ICSI, which suggests that PAWP levels can be a valid biomarker for successful fertilization and preimplantation development after ICSI (Aarabi et al. 2014a). Interestingly, similar results have been reported in animals (Kennedy et al. 2014), and the development of a multiplex flow cytometry test detecting PAWP, ubiquitinated protein aggregates and acrosomal integrity has provided predictive values for conception rates (Kennedy et al. 2014).

Tumor necrosis factor-related apoptosis-inducing ligand (TRAIL) is expressed as a type 2-membrane protein or a soluble cytokine. Although binding of TRIAL to its receptors induces an apoptotic response, other apoptosis-independent actions have been reported. The expression of TRAIL receptors (TRAIL1, TRAIL2, TRAIL3 and TRAIL4) was studied by flow cytometry (Zauli et al. 2014), and the presence of the soluble antiinflammatory cytokine was investigated. This study provided evidence of pro-survival and anti-inflammatory actions for TRAIL. Studies from our laboratory support this finding, as TNF $\alpha$ was able to activate the phosphorylation of JNK, suggesting a prosurvival effect (Morillo Rodriguez 2015). Receptors implicated in the acquisition of sperm motility have also been detected using flow cytometry in epididymal spermatozoa. These include the expression of a forward motility stimulation factor (FMSF), and a glycoprotein that promotes progressive motility of spermatozoa characterized in the corpus, cauda and caput of the epididymis (Dey et al. 2014b, Dey et al. 2014a). Flow cytometry has been used to study other aspects of epididymal sperm maturation, such as the acquisition of hyaluronidase 2 from epidydimal fluids, which, with its cofactor CD44, is necessary for fertilization. These factors permit the spermatozoon to penetrate extracellular matrix barriers containing hyaluronic acid 
(Modelski et al. 2014). Other proteins detected using flow cytometry that are potential sperm biomarkers include a truncated form of KIT tyrosine kinase (Muciaccia et al. 2010), the spermatic specific thioredoxin-3 protein (SPTRX-3) (Buckman et al. 2009) other thioredoxins, peroxiredoxins, ubiquitin and ubiquitin-like modifier proteins (Sutovsky et al. 2015). Nuclear proteins have also been investigated using flow cytometry (Zhong et al. 2015). H2AX is a member of the H2A histone family of proteins; the phosphorylation of the Ser-139 of H2AX forming $\gamma \mathrm{H} 2 \mathrm{AX}$ is an early cellular response to the induction of DNA double strand breaks. Measurement of $\gamma \mathrm{H} 2 \mathrm{AX}$ using flow cytometry revealed that the levels of this protein were higher in male infertile patients, which indicated that this analysis can be a powerful assay for evaluating DNA double-strand breaks in human spermatozoa (Zhong et al. 2015). In conclusion, the use of flow cytometry is increasing in spermatology, from its initial use to analyze single or simple parameters, to current multi-parametric analyses and proteomic applications (see fig 2 as an example). The rapid advance of this technique will likely result in the development of more sophisticated assays that are able to provide information about the multiple compartments and functions of spermatozoa simultaneously in a single assay. Moreover, the development of computational flow cytometry (Saeys et al. 2016, Levine et al. 2015) applied to sperm analysis will facilitate the interpretation of data and the extraction of additional information from each particular analysis (fig 3), this approach has been recently applied to the study of the stallion ejaculate (Ortega Ferrusola et al. 2016).

The trade of semen is the basis of the animal breeding industry, and male factor infertility affects a large proportion of couples seeking reproductive medicine interventions. In human patients, only $20 \%$ of cases can be correctly diagnosed, while the rest are classified as idiopathic or of unknown origin (Amaral et al. 2014a). 
However, semen analysis is still based on light microscopy to assess the sperm count, motility, morphology and membrane integrity based on dye exclusion assays. Many cases of male infertility remain undiagnosed. Recent developments in sperm biology are allowing new means to explore and diagnose this idiopathic infertility. The sperm proteome is being disclosed, and knowledge of the functionality of spermatozoa is also increasing. Discoveries in the sperm proteome using mass spectrometry approaches can be complemented with flow cytometry, allowing rapid assays to investigate sperm function at a single cell level that can be easily incorporated in andrology laboratories, facilitating the diagnosis of male infertility. In the animal breeding industry, flow cytometry assays based or completed with proteomic assays will largely improve the quality of doses, markedly increasing the profitability of the industry.

Implementation of these techniques (multiparametric and computational flow cytometry) combines the power of detection of multiple proteins with studies of protein functionality at the single cell level. This will lead to a rapid expansion of our knowledge of sperm biology, with applications to reproductive medicine and biotechnology. These facts will likely affect two major areas of development in spermatology; first diagnostic tests can be developed to target key proteins at a singlecell level in combination with functional assays. Second, our knowledge of sperm function will likely expand rapidly, resulting in better diagnostic assays, identification of therapeutically interesting targets and the potential development of treatments for male subfertility. Additionally, sperm biotechnologies will likely improve as a result of these developments.

\section{REFERENCES}

Aarabi M.; Balakier H.; Bashar S.; Moskovtsev S. I.; Sutovsky P.; Librach C. L.; Oko R., 2014a: Sperm content of postacrosomal WW binding protein is related to 
fertilization outcomes in patients undergoing assisted reproductive technology. Fertil Steril, 102 440-447.

Aarabi M.; Balakier H.; Bashar S.; Moskovtsev S. I.; Sutovsky P.; Librach C. L.; Oko R., 2014b: Sperm-derived WW domain-binding protein, PAWP, elicits calcium oscillations and oocyte activation in humans and mice. FASEB J, 28 4434-4440.

Aarabi M.; Sutovsky P.; Oko R., 2015: Re: Is PAWP the 'real' sperm factor? Asian J Androl, 17 446-449.

Abad C.; Amengual M. J.; Gosalvez J.; Coward K.; Hannaoui N.; Benet J.; Garcia-Peiro A.; Prats J., 2013: Effects of oral antioxidant treatment upon the dynamics of human sperm DNA fragmentation and subpopulations of sperm with highly degraded DNA. Andrologia, 45 211-216.

Abaigar T.; Holt W. V.; Harrison R. A.; del Barrio G., 1999: Sperm subpopulations in boar (Sus scrofa) and gazelle (Gazella dama mhorr) semen as revealed by pattern analysis of computer-assisted motility assessments. Biol Reprod, 60 3241.

Agarwal A.; Bertolla R. P.; Samanta L., 2016: Sperm proteomics: potential impact on male infertility treatment. Expert Rev Proteomics, 13 285-296.

Agarwal A.; Durairajanayagam D.; Halabi J.; Peng J.; Vazquez-Levin M., 2014: Proteomics, oxidative stress and male infertility. Reprod Biomed Online, 29 3258.

Aitken R. J., 2011: The capacitation-apoptosis highway: oxysterols and mammalian sperm function. Biol Reprod, 85 9-12.

Aitken R. J.; Baker M. A., 2008: The role of proteomics in understanding sperm cell biology. Int J Androl, 31 295-302.

Aitken R. J.; Curry B. J., 2011: Redox regulation of human sperm function: from the physiological control of sperm capacitation to the etiology of infertility and DNA damage in the germ line. Antioxid Redox Signal, 14 367-381.

Amaral A.; Castillo J.; Ramalho-Santos J.; Oliva R., 2014a: The combined human sperm proteome: cellular pathways and implications for basic and clinical science. Hum Reprod Update, 20 40-62.

Amaral A.; Paiva C.; Attardo Parrinello C.; Estanyol J. M.; Ballesca J. L.; RamalhoSantos J.; Oliva R., 2014b: Identification of proteins involved in human sperm motility using high-throughput differential proteomics. J Proteome Res, 13 5670-5684.

Azpiazu R.; Amaral A.; Castillo J.; Estanyol J. M.; Guimera M.; Ballesca J. L.; Balasch J.; Oliva R., 2014: High-throughput sperm differential proteomics suggests that epigenetic alterations contribute to failed assisted reproduction. Hum Reprod, 29 1225-1237.

Baker M. A., 2016: Proteomics of post-translational modifications of mammalian spermatozoa. Cell Tissue Res, 363 279-287.

Barazani Y.; Agarwal A.; Sabanegh E. S., Jr., 2014: Functional sperm testing and the role of proteomics in the evaluation of male infertility. Urology, 84 255-261.

Bayram H. L.; Claydon A. J.; Brownridge P. J.; Hurst J. L.; Mileham A.; Stockley P.; Beynon R. J.; Hammond D. E., 2016: Cross-species proteomics in analysis of mammalian sperm proteins. J Proteomics, 135 38-50.

Bhagwat S.; Dalvi V.; Chandrasekhar D.; Matthew T.; Acharya K.; Gajbhiye R.; Kulkarni V.; Sonawane S.; Ghosalkar M.; Parte P., 2014: Acetylated alphatubulin is reduced in individuals with poor sperm motility. Fertil Steril, 101 95104 e103. 
Buckman C.; George T. C.; Friend S.; Sutovsky M.; Miranda-Vizuete A.; Ozanon C.; Morrissey P.; Sutovsky P., 2009: High throughput, parallel imaging and biomarker quantification of human spermatozoa by ImageStream flow cytometry. Syst Biol Reprod Med, 55 244-251.

Buffone M. G.; Doncel G. F.; Marin Briggiler C. I.; Vazquez-Levin M. H.; Calamera J. C., 2004: Human sperm subpopulations: relationship between functional quality and protein tyrosine phosphorylation. Hum Reprod, 19 139-146.

Casao A.; Mata-Campuzano M.; Ordas L.; Cebrian-Perez J. A.; Muino-Blanco T.; Martinez-Pastor F., 2015: Cleaved PARP-1, an Apoptotic Marker, can be Detected in Ram Spermatozoa. Reprod Domest Anim, 50 688-691.

Castillo J.; Amaral A.; Azpiazu R.; Vavouri T.; Estanyol J. M.; Ballesca J. L.; Oliva R., 2014: Genomic and proteomic dissection and characterization of the human sperm chromatin. Mol Hum Reprod, 20 1041-1053.

Castillo J.; Estanyol J. M.; Ballesca J. L.; Oliva R., 2015: Human sperm chromatin epigenetic potential: genomics, proteomics, and male infertility. Asian J Androl, 17 601-609.

Chantler E.; Abraham-Peskir J.; Roberts C., 2004: Consistent presence of two normally distributed sperm subpopulations within normozoospermic human semen: a kinematic study. Int J Androl, 27 350-359.

Charlton B. G., 2007: Psychological neoteny and higher education: associations with delayed parenthood. Med Hypotheses, 69 237-240.

Cohen A. A.; Geva-Zatorsky N.; Eden E.; Frenkel-Morgenstern M.; Issaeva I.; Sigal A.; Milo R.; Cohen-Saidon C.; Liron Y.; Kam Z.; Cohen L.; Danon T.; Perzov N.; Alon U., 2008: Dynamic proteomics of individual cancer cells in response to a drug. Science, 322 1511-1516.

Cohen-Dayag A.; Tur-Kaspa I.; Dor J.; Mashiach S.; Eisenbach M., 1995: Sperm capacitation in humans is transient and correlates with chemotactic responsiveness to follicular factors. Proc Natl Acad Sci U S A, 92 11039-11043.

Correa-Perez J. R.; Fernandez-Pelegrina R.; Zavos P. M., 2003: Isolation of sequential sperm subpopulations and achievement of morphological normalcy in teratozoospermic specimens processed via a multi-layer/swim-up method. Andrologia, 35 248-249.

Davies R.; Vogelsang P.; Jonsson R.; Appel S., 2016: An optimized multiplex flow cytometry protocol for the analysis of intracellular signaling in peripheral blood mononuclear cells. J Immunol Methods, 436 58-63.

Davila M. P.; Munoz P. M.; Bolanos J. M.; Stout T. A.; Gadella B. M.; Tapia J. A.; da Silva C. B.; Ferrusola C. O.; Pena F. J., 2016: Mitochondrial ATP is required for the maintenance of membrane integrity in stallion spermatozoa, whereas motility requires both glycolysis and oxidative phosphorylation. Reproduction, 152 683-694.

Dey S.; Roy D.; Majumder G. C.; Bhattacharyya D., 2014a: Extracellular regulation of sperm transmembrane adenylyl cyclase by a forward motility stimulating protein. PLoS One, 9 e110669.

Dey S.; Roy D.; Majumder G. C.; Bhattacharyya D., 2014b: Receptor expression is essential for forward motility in the course of sperm cell maturation. Biochem Cell Biol, 92 43-52.

Dorado J.; Molina I.; Munoz-Serrano A.; Hidalgo M., 2010: Identification of sperm subpopulations with defined motility characteristics in ejaculates from Florida goats. Theriogenology, 74 795-804. 
Druart X.; Gatti J. L.; Huet S.; Dacheux J. L.; Humblot P., 2009: Hypotonic resistance of boar spermatozoa: sperm subpopulations and relationship with epididymal maturation and fertility. Reproduction, 137 205-213.

du Plessis S. S.; Kashou A. H.; Benjamin D. J.; Yadav S. P.; Agarwal A., 2011: Proteomics: a subcellular look at spermatozoa. Reprod Biol Endocrinol, 936.

Eisenbach M., 2003: Why are sperm cells phagocytosed by leukocytes in the female genital tract? Med Hypotheses, 60 590-592.

Eisenbach M.; Giojalas L. C., 2006: Sperm guidance in mammals - an unpaved road to the egg. Nat Rev Mol Cell Biol, 7 276-285.

Escoffier J.; Navarrete F.; Haddad D.; Santi C. M.; Darszon A.; Visconti P. E., 2015: Flow cytometry analysis reveals that only a subpopulation of mouse sperm undergoes hyperpolarization during capacitation. Biol Reprod, 92121.

Fraser R.; Lin C. J., 2016: Epigenetic reprogramming of the zygote in mice and men: on your marks, get set, go! Reproduction, 152 R211-R222.

Gakamsky A.; Schechtman E.; Caplan S. R.; Eisenbach M., 2008: Analysis of chemotaxis when the fraction of responsive cells is small--application to mammalian sperm guidance. Int J Dev Biol, 52 481-487.

Gallardo Bolanos J. M.; Balao da Silva C.; Martin Munoz P.; Plaza Davila M.; Ezquerra J.; Aparicio I. M.; Tapia J. A.; Ortega Ferrusola C.; Pena F. J., 2014a: Caspase activation, hydrogen peroxide production and Akt dephosphorylation occur during stallion sperm senescence. Reprod Domest Anim, 49 657-664.

Gallardo Bolanos J. M.; Balao da Silva C. M.; Martin Munoz P.; Morillo Rodriguez A.; Plaza Davila M.; Rodriguez-Martinez H.; Aparicio I. M.; Tapia J. A.; Ortega Ferrusola C.; Pena F. J., 2014b: Phosphorylated AKT preserves stallion sperm viability and motility by inhibiting caspases 3 and 7. Reproduction, 148 221235.

Gianzo M.; Munoa-Hoyos I.; Urizar-Arenaza I.; Larreategui Z.; Quintana F.; Garrido N.; Subiran N.; Irazusta J., 2016: Angiotensin II type 2 receptor is expressed in human sperm cells and is involved in sperm motility. Fertil Steril, 105 608-616.

Giojalas L. C.; Rovasio R. A.; Fabro G.; Gakamsky A.; Eisenbach M., 2004: Timing of sperm capacitation appears to be programmed according to egg availability in the female genital tract. Fertil Steril, 82 247-249.

Glassy M. C.; Surh C. D.; Sarkar S., 1984: Murine monoclonal antibodies that identify antigenically distinct subpopulations of human sperm. Hybridoma, 3 363-371.

Group A. S. I., 1998: Guidelines on the application of CASA technology in the analysis of spermatozoa. ESHRE Andrology Special Interest Group. European Society for Human Reproduction and Embryology. Hum Reprod, 13 142-145.

Gupta S.; Ghulmiyyah J.; Sharma R.; Halabi J.; Agarwal A., 2014: Power of proteomics in linking oxidative stress and female infertility. Biomed Res Int, 2014916212.

Hale M. B.; Nolan G. P., 2006: Phospho-specific flow cytometry: intersection of immunology and biochemistry at the single-cell level. Curr Opin Mol Ther, 8 215-224.

Hoppe P. S.; Coutu D. L.; Schroeder T., 2014: Single-cell technologies sharpen up mammalian stem cell research. Nat Cell Biol, 16 919-927.

Huang Y. L.; Fu Q.; Yang L.; Guan J. L.; Pan H.; Chen F. M.; Lu K. L.; Zhang M., 2015: Differences between high- and low-motility buffalo sperm identified by comparative proteomics. Reprod Domest Anim, 50 443-451.

Hunter R. H.; Rodriguez-Martinez H., 2002: Analysing mammalian fertilisation: reservations and potential pitfalls with an in vitro approach. Zygote, 10 11-15. 
Hunter R. H.; Rodriguez-Martinez H., 2004: Capacitation of mammalian spermatozoa in vivo, with a specific focus on events in the Fallopian tubes. Mol Reprod Dev, 67 243-250.

Jeong Y. J.; Kim M. K.; Song H. J.; Kang E. J.; Ock S. A.; Kumar B. M.; Balasubramanian S.; Rho G. J., 2009: Effect of alpha-tocopherol supplementation during boar semen cryopreservation on sperm characteristics and expression of apoptosis related genes. Cryobiology, 58 181-189.

Kennedy C. E.; Krieger K. B.; Sutovsky M.; Xu W.; Vargovic P.; Didion B. A.; Ellersieck M. R.; Hennessy M. E.; Verstegen J.; Oko R.; Sutovsky P., 2014: Protein expression pattern of PAWP in bull spermatozoa is associated with sperm quality and fertility following artificial insemination. Mol Reprod Dev, 81 436-449.

Kopeika J.; Thornhill A.; Khalaf Y., 2015: The effect of cryopreservation on the genome of gametes and embryos: principles of cryobiology and critical appraisal of the evidence. Hum Reprod Update, 21 209-227.

Krutzik P. O.; Irish J. M.; Nolan G. P.; Perez O. D., 2004: Analysis of protein phosphorylation and cellular signaling events by flow cytometry: techniques and clinical applications. Clin Immunol, 110 206-221.

Krutzik P. O.; Nolan G. P., 2003: Intracellular phospho-protein staining techniques for flow cytometry: monitoring single cell signaling events. Cytometry A, 55 61-70.

Kwon W. S.; Rahman M. S.; Lee J. S.; Kim J.; Yoon S. J.; Park Y. J.; You Y. A.; Hwang S.; Pang M. G., 2014: A comprehensive proteomic approach to identifying capacitation related proteins in boar spermatozoa. BMC Genomics, 15897.

Levine J. H.; Simonds E. F.; Bendall S. C.; Davis K. L.; Amir el A. D.; Tadmor M. D.; Litvin O.; Fienberg H. G.; Jager A.; Zunder E. R.; Finck R.; Gedman A. L.; Radtke I.; Downing J. R.; Pe'er D.; Nolan G. P., 2015: Data-Driven Phenotypic Dissection of AML Reveals Progenitor-like Cells that Correlate with Prognosis. Cell, 162 184-197.

Lindemann C. B.; Lesich K. A., 2016: Functional anatomy of the mammalian sperm flagellum. Cytoskeleton (Hoboken).

Liu Y.; Guo Y.; Song N.; Fan Y.; Li K.; Teng X.; Guo Q.; Ding Z., 2015: Proteomic pattern changes associated with obesity-induced asthenozoospermia. Andrology, 3 247-259.

Marti J. I.; Aparicio I. M.; Garcia-Herreros M., 2011: Sperm morphometric subpopulations are differentially distributed in rams with different maturity age in cryopreserved ejaculates. Theriogenology, 76 97-109.

Martin G.; Sabido O.; Durand P.; Levy R., 2004: Cryopreservation induces an apoptosis-like mechanism in bull sperm. Biol Reprod, 71 28-37.

Martin Munoz P.; Ortega Ferrusola C.; Anel Lopez L.; Del Petre C.; Alvarez Garcia M.; de Paz Cabello P.; Anel L.; Pena F., 2016: Caspase 3 Activity and Lipoperoxidative Status in Raw Semen Predict the Outcome of Cryopreservation of Stallion Spermatozoa. Biol Reprod.

Martin Munoz P.; Ortega Ferrusola C.; Vizuete G.; Plaza Davila M.; Rodriguez Martinez H.; Pena F. J., 2015: Depletion of Intracellular Thiols and Increased Production of 4-Hydroxynonenal that Occur During Cryopreservation of Stallion Spermatozoa Lead to Caspase Activation, Loss of Motility, and Cell Death. Biol Reprod, 93143. 
Martinez-Pastor F.; Garcia-Macias V.; Alvarez M.; Herraez P.; Anel L.; de Paz P., 2005: Sperm subpopulations in Iberian red deer epididymal sperm and their changes through the cryopreservation process. Biol Reprod, 72 316-327.

Mendoza N.; Casao A.; Del Valle I.; Serrano E.; Nicolau S.; Asumpcao M. E.; MuinoBlanco T.; Cebrian-Perez J. A.; Perez-Pe R., 2012: Quality characteristics and fertilizing ability of ram sperm subpopulations separated by partition in an aqueous two-phase system. J Chromatogr B Analyt Technol Biomed Life Sci, 880 74-81.

Modelski M. J.; Menlah G.; Wang Y.; Dash S.; Wu K.; Galileo D. S.; Martin-DeLeon P. A., 2014: Hyaluronidase 2: a novel germ cell hyaluronidase with epididymal expression and functional roles in mammalian sperm. Biol Reprod, 91109.

Morielli T.; O'Flaherty C., 2015: Oxidative stress impairs function and increases redox protein modifications in human spermatozoa. Reproduction, 149 113-123.

Morillo Rodriguez A. P. D. M., Miró Morán A, Martín Muñoz P, Balao da Silva C, Gallardo Bolaños JM, Ortega Ferrusola C, Tapia JA, Aparicio IM, Peña FJ 2015: Tumor necrosis factor alpha phosphorylates c-jun-N-terminal kinase in stallion spermatozoa:effect of cryopreservation Journal of Equine Veterinary Science, 35 206-2012.

Muciaccia B.; Sette C.; Paronetto M. P.; Barchi M.; Pensini S.; D'Agostino A.; Gandini L.; Geremia R.; Stefanini M.; Rossi P., 2010: Expression of a truncated form of KIT tyrosine kinase in human spermatozoa correlates with sperm DNA integrity. Hum Reprod, 25 2188-2202.

Newman J. R.; Ghaemmaghami S.; Ihmels J.; Breslow D. K.; Noble M.; DeRisi J. L.; Weissman J. S., 2006: Single-cell proteomic analysis of S. cerevisiae reveals the architecture of biological noise. Nature, 441 840-846.

Newman J. R.; Weissman J. S., 2006: Systems biology: many things from one. Nature, 444 561-562.

Nicholas K. J.; Greenplate A. R.; Flaherty D. K.; Matlock B. K.; Juan J. S.; Smith R. M.; Irish J. M.; Kalams S. A., 2016: Multiparameter analysis of stimulated human peripheral blood mononuclear cells: A comparison of mass and fluorescence cytometry. Cytometry A, 89 271-280.

Nunez-Martinez I.; Moran J. M.; Pena F. J., 2006: A three-step statistical procedure to identify sperm kinematic subpopulations in canine ejaculates: changes after cryopreservation. Reprod Domest Anim, 41 408-415.

Nunez-Martinez I.; Moran J. M.; Pena F. J., 2007: Identification of sperm morphometric subpopulations in the canine ejaculate: do they reflect different subpopulations in sperm chromatin integrity? Zygote, 15 257-266.

O'Flaherty C., 2015: Redox regulation of mammalian sperm capacitation. Asian J Androl, 17 583-590.

Oberprieler N. G.; Tasken K., 2011: Analysing phosphorylation-based signalling networks by phospho flow cytometry. Cell Signal, 23 14-18.

Oren-Benaroya R.; Orvieto R.; Gakamsky A.; Pinchasov M.; Eisenbach M., 2008: The sperm chemoattractant secreted from human cumulus cells is progesterone. Hum Reprod, 23 2339-2345.

Ortega Ferrusola C.; Anel-Lopez L.; Martin-muNoz P.; Ortiz Rodriguez J. M.; Gil M. C.; Alvarez M.; De Paz P.; Ezquerra J.; Masot J.; Redondo E.; Anel L.; Pena F. J., 2016: Computational flow cytometry reveals that cryopreservation induces spermptosis. Reproduction.

Ortega-Ferrusola C.; Macias Garcia B.; Suarez Rama V.; Gallardo-Bolanos J. M.; Gonzalez-Fernandez L.; Tapia J. A.; Rodriguez-Martinez H.; Pena F. J., 2009: 
Identification of sperm subpopulations in stallion ejaculates: changes after cryopreservation and comparison with traditional statistics. Reprod Domest Anim, 44 419-423.

Ortega-Ferrusola C.; Sotillo-Galan Y.; Varela-Fernandez E.; Gallardo-Bolanos J. M.; Muriel A.; Gonzalez-Fernandez L.; Tapia J. A.; Pena F. J., 2008: Detection of "apoptosis-like" changes during the cryopreservation process in equine sperm. J Androl, 29 213-221.

Ozkosem B.; Feinstein S. I.; Fisher A. B.; O'Flaherty C., 2015: Advancing age increases sperm chromatin damage and impairs fertility in peroxiredoxin 6 null mice. Redox Biol, 5 15-23.

Paradisi R.; Bellavia E.; Pession A. L.; Venturoli S.; Bach V.; Flamigni C., 1996: Characterization of human sperm antigens reacting with antisperm antibodies from autologous sera and seminal plasma: comparison among infertile subpopulations. Int J Androl, 19 345-352.

Pena F. J.; Garcia B. M.; Samper J. C.; Aparicio I. M.; Tapia J. A.; Ferrusola C. O., 2011: Dissecting the molecular damage to stallion spermatozoa: the way to improve current cryopreservation protocols? Theriogenology, 76 1177-1186.

Pena F. J.; Johannisson A.; Wallgren M.; Rodriguez-Martinez H., 2003: Assessment of fresh and frozen-thawed boar semen using an Annexin-V assay: a new method of evaluating sperm membrane integrity. Theriogenology, 60 677-689.

Pena F. J.; Ortega Ferrusola C.; Martin Munoz P., 2016: New flow cytometry approaches in equine andrology. Theriogenology.

Pena F. J.; Plaza Davila M.; Ball B. A.; Squires E. L.; Martin Munoz P.; Ortega Ferrusola C.; Balao da Silva C., 2015: The Impact of Reproductive Technologies on Stallion Mitochondrial Function. Reprod Domest Anim, 50 529-537.

Pena F. J.; Saravia F.; Garcia-Herreros M.; Nunez-martinez I.; Tapia J. A.; Johannisson A.; Wallgren M.; Rodriguez-Martinez H., 2005a: Identification of sperm morphometric subpopulations in two different portions of the boar ejaculate and its relation to postthaw quality. J Androl, 26 716-723.

Pena F. J.; Saravia F.; Johannisson A.; Walgren M.; Rodriguez-Martinez H., 2005b: A new and simple method to evaluate early membrane changes in frozen-thawed boar spermatozoa. Int J Androl, 28 107-114.

Pena F. J.; Saravia F.; Nunez-Martinez I.; Johannisson A.; Wallgren M.; Rodriguez Martinez H., 2006: Do different portions of the boar ejaculate vary in their ability to sustain cryopreservation? Anim Reprod Sci, 93 101-113.

Perez O. D.; Nolan G. P., 2006: Phospho-proteomic immune analysis by flow cytometry: from mechanism to translational medicine at the single-cell level. Immunol Rev, 210 208-228.

Polat A. N.; Ozlu N., 2014: Towards single-cell LC-MS phosphoproteomics. Analyst, 139 4733-4749.

Quintero-Moreno A.; Rigau T.; Rodriguez-Gil J. E., 2007: Multivariate cluster analysis regression procedures as tools to identify motile sperm subpopulations in rabbit semen and to predict semen fertility and litter size. Reprod Domest Anim, 42 312-319.

Roca J.; Parrilla I.; Gil M. A.; Cuello C.; Martinez E. A.; Rodriguez-Martinez H., 2016: Non-viable sperm in the ejaculate: Lethal escorts for contemporary viable sperm. Anim Reprod Sci, 169 24-31.

Rodriguez-Martinez H., 1992: Sperm production in the stallion. Acta Vet Scand Suppl, 88 9-28. 
Saadatpour A.; Lai S.; Guo G.; Yuan G. C., 2015: Single-Cell Analysis in Cancer Genomics. Trends Genet, 31 576-586.

Saeys Y.; Gassen S. V.; Lambrecht B. N., 2016: Computational flow cytometry: helping to make sense of high-dimensional immunology data. Nat Rev Immunol, 16 449-462.

Sakkas D.; Ramalingam M.; Garrido N.; Barratt C. L., 2015: Sperm selection in natural conception: what can we learn from Mother Nature to improve assisted reproduction outcomes? Hum Reprod Update, 21 711-726.

Santolaria P.; Vicente-Fiel S.; Palacin I.; Fantova E.; Blasco M. E.; Silvestre M. A.; Yaniz J. L., 2015: Predictive capacity of sperm quality parameters and sperm subpopulations on field fertility after artificial insemination in sheep. Anim Reprod Sci, 163 82-88.

Satake N.; Elliott R. M.; Watson P. F.; Holt W. V., 2006: Sperm selection and competition in pigs may be mediated by the differential motility activation and suppression of sperm subpopulations within the oviduct. J Exp Biol, 209 15601572.

Sigal A.; Milo R.; Cohen A.; Geva-Zatorsky N.; Klein Y.; Liron Y.; Rosenfeld N.; Danon T.; Perzov N.; Alon U., 2006: Variability and memory of protein levels in human cells. Nature, 444 643-646.

Spitzer M. H.; Nolan G. P., 2016: Mass Cytometry: Single Cells, Many Features. Cell, 165 780-791.

Sutovsky P.; Aarabi M.; Miranda-Vizuete A.; Oko R., 2015: Negative biomarker based male fertility evaluation: Sperm phenotypes associated with molecular-level anomalies. Asian J Androl, 17 554-560.

Swegen A.; Curry B. J.; Gibb Z.; Lambourne S. R.; Smith N. D.; Aitken R. J., 2015: Investigation of the stallion sperm proteome by mass spectrometry. Reproduction, 149 235-244.

Tang C. H.; Wu M. P.; Liu J. T.; Lin H. C.; Hsu C. C., 2006: Delayed parenthood and the risk of cesarean delivery--is paternal age an independent risk factor? Birth, 33 18-26.

Tarin J. J.; Brines J.; Cano A., 1998: Long-term effects of delayed parenthood. Hum Reprod, 13 2371-2376.

Thilagavathi J.; Venkatesh S.; Kumar R.; Dada R., 2012: Segregation of sperm subpopulations in normozoospermic infertile men. Syst Biol Reprod Med, 58 313-318.

Thomson L. K.; Fleming S. D.; Aitken R. J.; De Iuliis G. N.; Zieschang J. A.; Clark A. M., 2009: Cryopreservation-induced human sperm DNA damage is predominantly mediated by oxidative stress rather than apoptosis. Hum Reprod, 24 2061-2070.

Thurston L. M.; Watson P. F.; Holt W. V., 1999: Sources of variation in the morphological characteristics of sperm subpopulations assessed objectively by a novel automated sperm morphology analysis system. J Reprod Fertil, 117 271280.

Thurston L. M.; Watson P. F.; Mileham A. J.; Holt W. V., 2001: Morphologically distinct sperm subpopulations defined by Fourier shape descriptors in fresh ejaculates correlate with variation in boar semen quality following cryopreservation. J Androl, 22 382-394.

Unates D. R.; Guidobaldi H. A.; Gatica L. V.; Cubilla M. A.; Teves M. E.; Moreno A.; Giojalas L. C., 2014: Versatile action of picomolar gradients of progesterone on different sperm subpopulations. PLoS One, 9 e91181. 
Zauli G.; Celeghini C.; Monasta L.; Martinelli M.; Luppi S.; Gonelli A.; Grill V.; Ricci G.; Secchiero P., 2014: Soluble TRAIL is present at high concentrations in seminal plasma and promotes spermatozoa survival. Reproduction, 148 191198.

Zhong H. Z.; Lv F. T.; Deng X. L.; Hu Y.; Xie D. N.; Lin B.; Mo Z. N.; Lin F. Q., 2015: Evaluating gammaH2AX in spermatozoa from male infertility patients. Fertil Steril, 104 574-581.

\section{FIGURE LEGENDS}

Fig 1. - Comparison of flow cytometry versus western blotting to identify individual proteins. In this experiment, four different expression levels of a protein are detected using western blotting. When the same protein is detected using flow cytometry, different situations can be detected; in one, the signal detected in WB can be due to a single population of spermatozoa expressing the protein of interest or to the presence of two populations of spermatozoa, one with high expression of the protein of interest and another population not expressing the protein; WB cannot discriminate between the two. Similar situations are depicted in 2-4 (Krutzik et al. 2004).

Fig 2.- Example of a multiparamater panel; in A spermatozoa are gated based in H33342 content and this gate is used to determine the integrity of the sperm membranes in B. In B three sperm subpopulations are easily gated representing live spermatozoa, and dead spermatozoa with a intermediate population classified as “?”. In C these three subpopulations are further investigated for the presence of active caspase 3 that only was present in the “?” population and in dead spermatozoa. In D three populations are classified in function of the presence of caspase 3, and the presence of 4-HNE in the is 
investigated in D where overlay histograms show that 4-HNE is expressed in apoptotic spermatozoa.

Fig 3. - Example of computational cytometry applied to the analysis of protein expression at the single-cell level using Flow cytometry; data were analyzed using automatic classification of cellular expression by non linear stochastic embedding (ACCENSE). In figures A-F characteristics in raw semen are studied; in plots G-L characteristics of the same ejaculates after cryopreservation are depicted. A and F G represent t-SNE maps, each point represent an spermatozoa, $\mathrm{B}$ and $\mathrm{H}$ represent subpopulations identified in the ejaculate C and I represent the H33342 channel, D and J represent the Caspase 3 channel, $\mathrm{E}$ and $\mathrm{K}$ represent the ethidium channel, $\mathrm{F}$ and $\mathrm{L}$ represent the CellRox (identification of ROS) channel. A heat map at the right of each plot quantify the expression level of each marker. 
Table 1. - Recent studies using flow cytometry to investigate sperm proteins in humans and animals

\begin{tabular}{|c|c|c|c|}
\hline Study reference & Type of sperm & Protein studied & Main conclusions \\
\hline Martin Muñoz et al 2015 & Stallion Spermatozoa & Caspase 3 & $\begin{array}{l}\text { 4-hydroxinonenal is related to } \\
\text { caspase activation }\end{array}$ \\
\hline Liu et al (2015) & $\begin{array}{l}\text { Human spermatozoa } \\
\text { (obese patients) }\end{array}$ & ERp57 and ACTRT2 & $\begin{array}{l}\text { Both proteins are reduced in } \\
\text { obesity-induced } \\
\text { asthenozoospermia }\end{array}$ \\
\hline Bhagwat et al (2014) & $\begin{array}{l}\text { Human spermatozoa, } \\
\text { normozoospermic and } \\
\text { asthenozoospermic patients }\end{array}$ & $\begin{array}{l}\alpha \text {-tubulin, acetylated } \alpha \text {-tubulin and } \\
\text { isoforms TUBA3C, TUBA4A and } \\
\text { TUBA8 }\end{array}$ & $\begin{array}{l}\text { a-tubulin acetylation is } \\
\text { associated } \\
\text { asthenozoospermia }\end{array}$ \\
\hline Gallardo Bolaños et al (2014) & Stallion Spermatozoa & Phospho-Akt & $\begin{array}{l}\text { De-phosphorylation of Akt leads } \\
\text { to caspase } 3 \text { activation and } \\
\text { sperm senescence }\end{array}$ \\
\hline Ortega Ferrusola et al (2009) & Stallion Spermatozoa & Caspase 3 & Caspase 3 is cleaved during \\
\hline
\end{tabular}




\begin{tabular}{|c|c|c|c|}
\hline & & & cryopreservation \\
\hline Yeung and Cooper (2007) & Human spermatozoa & $\begin{array}{l}\text { K+ Channels (KCNE1, KCNA5, } \\
\text { KCNK5) }\end{array}$ & $\begin{array}{l}\text { KCNE1 is the major channel } \\
\text { regulating volume decrease in } \\
\text { human spermatozoa }\end{array}$ \\
\hline Gianzo et al (2016) & Human spermatozoa & $\begin{array}{lllll}\text { Angiotensin } & \text { II type } 2 & \text { receptor } \\
\text { (AT2R) } & & & & \\
\text { (AT) } & & & \end{array}$ & $\begin{array}{l}\text { AT2R levels were lower in } \\
\text { asthenozoospermic patients }\end{array}$ \\
\hline Aarabi et al (2014) & Human spermatozoa & $\begin{array}{l}\text { Postacrosomal WW binding protein } \\
\text { (PAWP or WBP2NL) }\end{array}$ & $\begin{array}{l}\text { PAWP expression levels were } \\
\text { correlated with embryonic } \\
\text { development after ICSI }\end{array}$ \\
\hline Zauli et al (2014) & Human spermatozoa & $\begin{array}{l}\text { Tumor necrosis factor-related } \\
\text { apoptosis-inducing ligand receptors } \\
\text { (TRAIL1-4) }\end{array}$ & $\begin{array}{l}\text { TRAIL 1-4 are expressed in } \\
\text { human spermatozoa and soluble } \\
\text { TRAIL may enhance sperm } \\
\text { survival in capacitated } \\
\text { spermatozoa }\end{array}$ \\
\hline Kennedy et al (2014) & Bull spermatozoa & Postacrosomal WW binding protein & PAWN is a potential biomarker \\
\hline
\end{tabular}




\begin{tabular}{|c|c|c|c|}
\hline & & (PAWP or WBP2NL) & of bull fertility \\
\hline Zhong et al 2016 & Human spermatozoa & $\gamma \mathrm{H} 2 \mathrm{AX}$ & $\begin{array}{l}\gamma \mathrm{H} 2 \mathrm{AX} \text { levels are higher in the } \\
\text { sperm of male infertility } \\
\text { patients. Evaluation of this } \\
\text { protein using FC can be a useful } \\
\text { biomarker of double strand } \\
\text { breaks in DNA }\end{array}$ \\
\hline Casao et al 2015 & Ram spermatozoa & $\begin{array}{l}\text { Cleaved poly ADP ribose polymerase } \\
\text { (cPARP) }\end{array}$ & $\begin{array}{l}\text { Apoptosis } \\
\text { staurosporine or betulinic acid } \\
\text { increase cPARP in ram } \\
\text { spermatozoa }\end{array}$ \\
\hline
\end{tabular}

